\title{
BENTUK PERTUNJUKAN DAN FUNGSI BUNDENGAN WONOSOBO
}

\author{
Bahtiar Arbi ${ }^{1}$, Richard Junior Kapoyos ${ }^{2}$ \\ Universitas Negeri Semarang ${ }^{1}$ \\ bahtiararbi93@gmail.com ${ }^{1}$ \\ Sekolah Tinggi Theologia Abdiel ${ }^{2}$ \\ richardkapojos@gmail.com²
}

\begin{abstract}
Abstrak
Bundengan merupakan alat musik yang bertransformasi dari kowangan atau tudhung. Kowangan merupakan semacam penutup kepala yang terbuat dari bilah bambu, clumpring, dan tali ijuk yang biasa digunakan penggembala bebek untuk berlindung dari hujan dan sinar matahari. Bundengan digunakan sebagai pengiring tarian seperti pada Lengger dan Soreng. Tujuan dari penelitian ini adalah untuk menganalisis bentuk pertunjukan dan fungsi kesenian bundengan. Penelitian ini menggunakan metode kualitatif dengan teknik pengumpulan data wawancara, observasi, dan studi dokumen. Teknik validitas data didasarkan pada kriteria kredibilitas, dengan menggunakan triangulasi data, sedangkan teknik analisis data melalui pengumpulan, penyajian, reduksi, dan verifikasi data. Pendekatan penelitian ini menggunakan pendekatan kualitatif interdisiplin, dengan kajian intraestetik pada bentuk musik dan ekstraestetik pada fungsi musik. Hasil penelitian ini menunjukkan bahwa bentuk pertunjukan bundengan mengimitasi suara gamelan (bendhe, kempul, gong, dan kendang) yang diaplikasikan pada pola permainannya untuk mengiringi tarian Lengger Topeng. Sedangkan fungsi musik bundengan yaitu sebagai pengiring tarian, ungkapan emosi, penghayatan estetis, hiburan, komunikasi, berkaitan dengan norma-norma sosial, kesinambungan kebudayaan, dan pengintegrasian masyarakat.
\end{abstract}

Kata kunci: bundengan; fungsi; seni pertunjukan

\begin{abstract}
Bundengan is a musical instrument that is transformed from kowangan or tudhung. Kowangan is a kind of head covering made from bamboo slats, clumpring, and palm fibers that are used by duck herders to protect them from rain and sunlight. Bundengan is used as a dance accompaniment as in Lengger and Soreng. The purpose of this study is to analyze the form of performance and function of bundengan art. This study uses qualitative methods with data collection techniques interviews, observation, and study documents. Data validity techniques are based on credibility criteria, using data triangulation, while data analysis techniques are through data collection, presentation, reduction, and verification. This research approach uses an interdisciplinary qualitative approach, with intraesthetic studies on music forms and extraesthetics on music functions. The results of this study indicate that the form of the bundengan imitates the sound of gamelan (bendhe, kempul, gong, and kendang) applied to the pattern of the game to accompany the Lengger Topeng dance. While the function of bundengan music is as a dance accompaniment, emotional expression, aesthetic appreciation, entertainment, communication, related to social norms, cultural continuity, and community integration.
\end{abstract}

Keywords: bundengan; function; performing arts

\section{Pendahuluan}

Alat musik Bundengan dapat dikatakan fenomenal karena alat musik ini dapat membuat orang terheran-heran ketika pertama kali melihat dan mendengar suaranya. Kesan unik, antik, kuno, artistik dapat dirasakan ketika pertama kali melihat maupun 
mendengarkan suaranya. Pada awalnya bundengan bukan merupakan sebuah alat musik, namun semacam alat untuk berteduh dari hujan maupun panas matahari yang digunakan oleh masyarakat tradisional agraris. Sebelum ditemukannya payung maupun mantel, masyarakat menggunakan alat teduh yang sering disebut dengan nama kowangan atau tudhung yang dalam bahasa Indonesia berarti penutup kepala.

Kowangan atau tudhung memiliki bentuk seperti mantel yang diletakan di kepala, dan panjanganya dapat sampai setengah betis orang dewasa. Kowangan digunakan oleh para penggembala untuk angon bebek di sawah maupun ladang. Istilah kowangan populer di daerah eks Karisidenan Kedu, tetapi tidak menutup kemungkinan di tempat lain juga terdapat benda serupa namun dengan istilah yang berbeda. Menurut Wuryanto (2017), budayawan Wonosobo, bundengan adalah alat musik tradisional yang sudah sangat langka, dengan terbuat dari kerangka welat bambu tebal yang dianyam dan bagian luarnya dilapisi dengan clumpring (pembungkus ruas bambu) dan diikat dengan menggunakan tali ijuk. Bentuk kowangan dapat dilihat pada gambar 1.

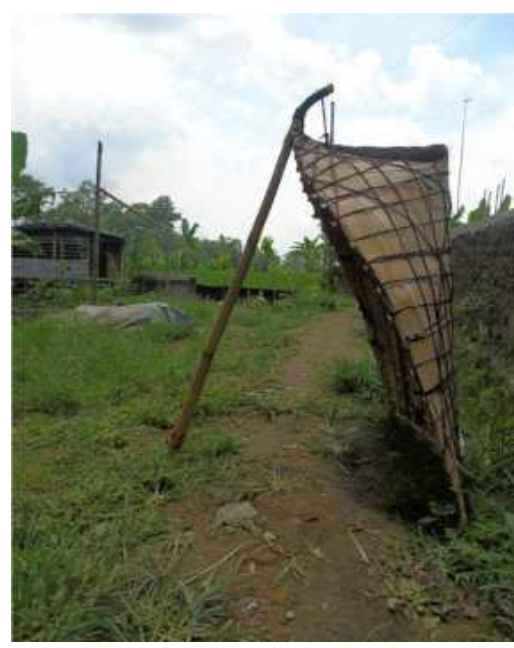

Gambar 1. Kowangan

(Dokumentasi: Sa'id Abdulloh, 2015)

Pendapat serupa juga dijelaskan Kunst (1973) yang mendeskripsikan kowangan sebagai instrumen musik dengan konstruksi seperti perisai yang di dalamnya terdapat beberapa helai senar yang disusun secara horizontal dengan potongan bambu kecil di tengahnya dan beberapa potongan bambu yang ditancapkan dengan ukuran yang tidak sama dan keduanya dapat menghasilkan suara. Beranjak dari beberapa definisi yang telah dijelaskan, dapat diinterpretasikan bahwa bundengan merupakan sebuah alat musik dimana kowangan berfungsi sebagai konstruksi dasarnya, dengan penambahan beberapa dawai dan bilah bambu sebagai komponen pelengkapnya. 
Berdasarkan temuan Jaap Kunst dalam bukunya Music in Java (1973), bundengan diklasifikasikan sebagai bagian dari alat musik chordophone dan idophone yang dapat ditemukan di beberapa wilayah di sekitar Karisidenan Kedu dengan penamaan yang berbeda-beda. Di Wonosobo dikenal dengan kowangan yang ketika menjadi alat musik berubah nama menjadi bundengan, sedangkan di Temanggung terdapat payung krudhuk yang ketika menjadi alat musik berubah nama menjadi cengklungan. Alat musik ini juga ditemukan di daerah Ampel (Boyolali), Sukareja (Kendal), Banjarnegara, dan di daerah Cherme (Gresik). Kemudian ada pula istilah lain dari kowangan yaitu gowangan, chelempungan atau chaping buyuk.

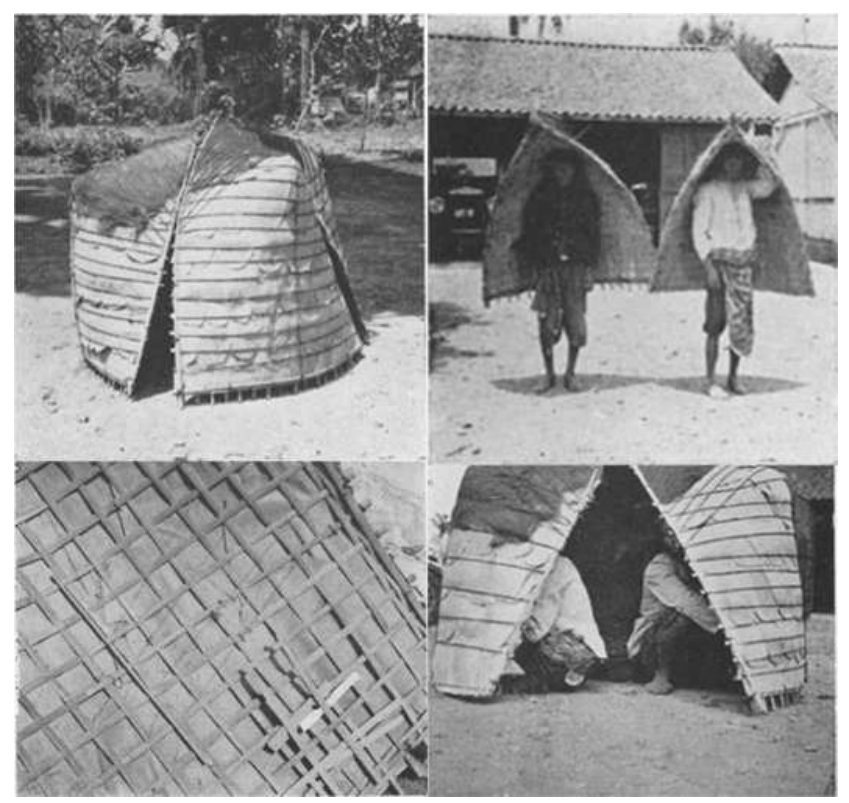

Gambar 2. Kowangan yang dijumpai Jaap Kunst dalam bukunya Music in Java. (Dokumentasi: Jaap Kunst, 1973)

Selain itu Keen (2017), seorang etnomusikolog dari Amerika dalam artikelnya "Bundengan Stories: Folk Zithers and Duck Herders in Wonosobo, Central Java (2017)", mengungkapkan bahwa terdapat seorang konservator dari Australia bernama Rosie Cook yang menghubunginya dan menanyakan instrumen kowangan. Rosie Cook menemukan kowangan kuno di koleksi arsip musik Monash University Melbourne yang dibawa oleh etnomusikolog asal Indonesia bernama Prof. Margaret Kartomi dari daerah Dataran Tinggi Dieng pada tahun 1970an. Bentuk dari kowangan kuno itu dapat dilihat pada gambar 3. 


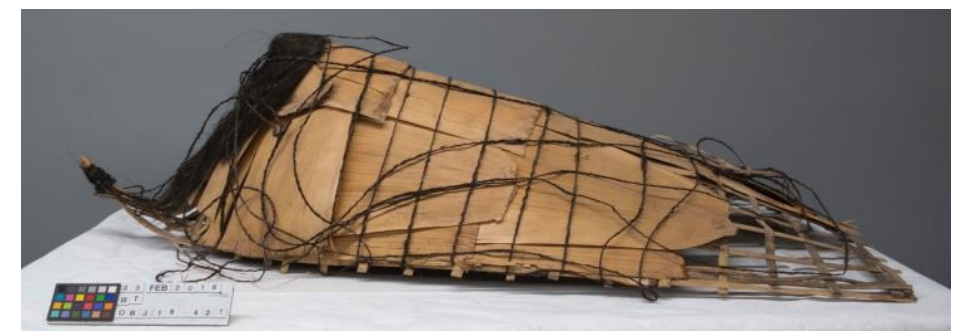

Gambar 3. Kowangan di Museum Monash University Melbourne, Australia

(Dokumentasi: Rosie Cook, 2016)

Paparan para peneliti bundengan terdahulu dapat memberikan gambaran historis dan dijadikan sebagai dasar pijakan untuk mengkaji lebih lanjut mengenai alat musik chordophone ini, yang mana gaungnya sudah sampai ke benua lain. Riwayat panjang perjalanan bundengan, mendapat tempat istimewa diantara para peneliti modern maupun kontemporer. Masih sedikitnya artikel terkait historiografi bundengan karena alat musik ini pada awalnya hanya diwariskan secara turun temurun.

Alat musik bundengan di era modern pertama kali ditemukan kembali oleh Bapak Barnawi sekitar tahun 1968. Akan tetapi, berdasarkan bukti sejarah yang ditemukan, keberadaan bundengan ternyata jauh lebih tua dibanding perkiraannya. Hal ini dibuktikan dengan tulisan di kitab Wretta Sancaya karya Mpu Tanakung pada masa Kerajaan Majapahit sekitar abad ke-12. Dalam kitab ini terdapat kalimat mengenai musik yang disebut "tudhung", para ahli Jawa beranggapan bahwa konotasi dari "tudhung" sebagai penutup kepala itu mengacu pada kowangan (Abdulloh, 2017).

Alat musik bundengan biasa digunakan untuk mengiringi tarian Jaran Kepang, Topeng, dan Lengger dengan membawakan tembang-tembang pengiring seperti Kebo Giro, Sulasih, Gones, Sumiyar, Kinayakan, Bribil, dan Cuthang. Alat musik bundengan merupakan salah satu alat musik yang tergolong ajaib, unik, dan istimewa karena bundengan dapat mereplika beragam suara pada beberapa perangkat gamelan seperti Bendhe, Kempul, Gong, dan Kendang. Pada era Majapahit, terdapat musik kerajaan dan musik rakyat. Gamelan hanya dapat dinikmati oleh kalangan bangsawan dan kerajaan, lain halnya dengan rakyat jelata yang hanya dapat mendengar suara khas dari alunan Gamelan tanpa melihat secara langsung. Oleh karena itu, kowangan kemudian bertransformasi menjadi alat musik yang dapat mengimitasi suara Gamelan dengan menggunakan rumput grinting sebagai dawai, dan bilah bambu sebagai kendangnya.

Kesenian bundengan juga sudah dibuat film dokumenter khusus yang berjudul “Aura Magis Musik Bundengan” oleh para seniman yang berkolaborasi dengan pemerintah 
daerah setempat yang dirilis pada awal Februari 2016 (Hengky, 2016). Selain diliput di media massa dan di filmkan, kesenian bundengan juga pernah diteliti oleh Cook (2016), seorang conservatory dari Monash University Australia pada tahun 2016. Selain melakukan penelitian, Rosieh Cook juga membawa beberapa bundengan ke negerinya. Ada pula seorang etnomusikolog Amerika bernama Palmer Keen, yang meneliti banyak kesenian tradisional di Indonesia dan penelitianya dapat diakses melalui situs www.auralarchipelago.com.

Artikel ini membahas mengenai bentuk pertunjukan dan fungsi musik bundengan sebagai iringan tari Lengger. Djelantik (1999) mengungkapkan bahwa bentuk merupakan unsur-unsur dasar dari susunan pertunjukan. Unsur-unsur penunjang yang membantu bentuk dalam mencapai perwujudannya yang khas adalah seniman, alat musik, kostum dan rias, lagu yang disajikan, tempat pertunjukan, waktu, serta penonton. Pengertian penyajian menurut Djelantik (1999) yaitu bagaimana kesenian itu disuguhkan kepada yang menyaksikannya, penonton, para pengamat, pembaca, pendengar, khalayak ramai pada umumnya. Sedangkan unsur yang berperan dalam penampilan atau penyajian adalah bakat, keterampilan, serta sarana atau media.

Fungsi dan perkembangan sebuah kesenian tentunya tidak terlepas dari masyarakat pendukungnya yang turut serta dalam memengaruhi kesenian tersebut (Kapoyos, 2018). Pembahasan mengenai fungsi musik menggunakan teori dari Meriam (1964) dalam bukunya The Antropologi of Music yang mengelompokkan fungsi musik ke dalam sepuluh fungsi. Adapun fungsi yang diungkapkannya adalah sebagai ungkapan emosi, penghayatan estetis, hiburan, perlambangan, komunikasi, reaksi jasmani, fungsi yang berkaitan dengan norma-norma sosial, pengesahan lembaga sosial, kesinambungan kebudayaan, dan pengintegrasian masyarakat. Dalam melakukan penelitian, fungsi-fungsi itu disesuaikan dengan data yang didapatkan penulis pada saat penelitian.

Fenomena sebagaimana dipaparkan di atas sangat menarik untuk diteliti karena alat musik bundengan merupakan alat musik etnik dan kuno yang keberadaannya sudah ada sejak kerajaan Majapahit. Evolusi bundengan yang semula berfungsi sebagai alat berteduh kemudian menjadi sebuat alat musik merupakan hal menarik untuk dilakukan pengkajian lebih lanjut. Beberapa isu terkait hal tersebut kiranya menjadi alasan yang kuat bagi penulis untuk ditulis menjadi artikel. 


\section{Metode Penelitian}

Penelitian ini menggunakan pendekatan kualitatif interdisiplin, dengan kajian intraestetik yang mengkaji tentang bentuk musik dan ekstraestetik mengkaji mengenai fungsi musik. Fokus penelitian ini mengenai bentuk pertunjukan dan fungsi kesenian musik bundengan. Teknik pengumpulan data menggunakan wawancara, observasi, dan studi dokumen, sedangkan analisis data yang digunakan mengacu pada analisis Miles \& Huberman (1992), dimana proses analisis datanya dilakukan secara serempak mulai dari proses pengumpulan data, mereduksi, mengklarifikasi, mendeskripsikan, menyimpulkan dan menginterpretasikan semua informasi secara selektif.

\section{Bentuk Pertunjukan Musik Bundengan}

Kowangan atau tudhung merupakan prototipe awal alat musik bundengan dan sangat erat kaitanya dengan kehidupan masyarakat pada masanya. Penggunaan kowangan tentunya tidak terlepas dari kegiatan sehari-hari masyarakat pada zamannya seperti bertani, berternak, dan menggembala. Dalam perkembangannya, kowangan kemudian berevolusi menjadi alat musik bundengan. Kowangan terbuat dari bilah bambu yang dilapisi dengan clumpring dan diikat menggunakan tali ijuk. Bahan baku tersebut mudah didapatkan di daerah Wonosobo.

Pertunjukan bundengan biasanya dimainkan oleh satu orang yang menggunakan satu kowangan tanpa ada tambahan instrumen lain. Sedangkan penembangnya dapat dilakukan oleh pemain bundengan itu sendiri ataupun ditembangkan orang lain. Kesenian bundengan yang diteliti ini hanya dimainkan oleh satu orang atau disebut dengan istilah one man show. Dengan demikian kesenian bundengan ini hanya disajikan oleh satu orang yang berperan memainkan bundengan sekaligus menyanyikan tembang-tembang Jawa. Namun dalam perkembangannya, penyajian bundengan juga dimainkan secara kolosal dan tidak hanya mengiringi tembang-tembang Jawa namun juga lagu-lagu pop modern. Bentuk pertunjukannya dapat dilihat pada gambar 4. 


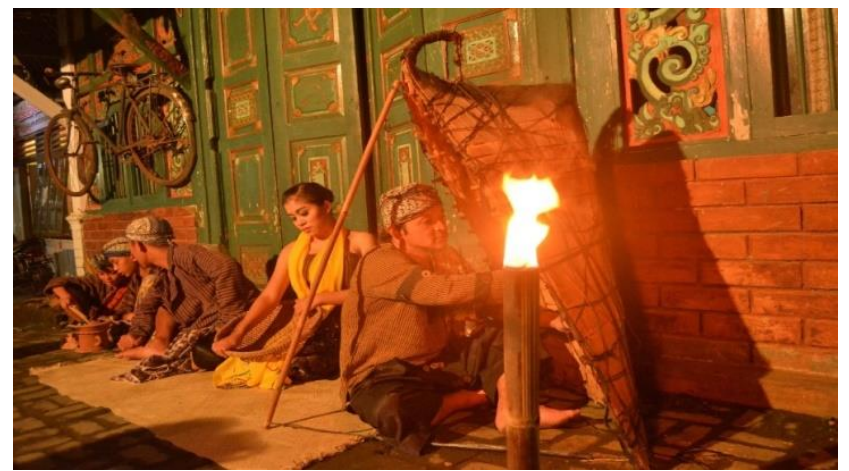

Gambar 4. Pertunjukan Bundengan di Wonosobo

(Dokumentasi: Bahtiar Arbi, 2017)

Dalam instrumen bundengan pada gambar 5 terdapat pengaturan dawai thong (nada 5), dhil (nada 3), dhung (nada 6), dheng (gong). Dawai tersebut merupakan imitasi bunyi dari instrumen gamelan yang berbentuk pencu. Pada instrumen bendhe dimainkan oleh dawai thong dan dhil, kemudian instrumen kempul dimainkan oleh dawai dhung, serta instrumen gong oleh dawai dheng. Unsur lain dalam tudung adalah ingis atau bilah bambu dengan bunyi dhah, thung, tak yang mana diatur menyerupai bunyi kendang. Kedua unsur bunyi itu dimainkan secara bersama oleh satu orang. Pada waktu itu dimainkan oleh Barnawi dan Bukhori sebagai vokalnya. Bapak Barnawi menurut para seniman Wonosobo dikenal sebagai orang yang sangat berjasa dalam memopulerkan bundengan. Beliau juga berjasa merubah ijuk dengan senar raket pada komponen string, dan menambahkan alat stem dari ranting bambu yang sampai saat ini masih diterapkan pada generasi sekarang (Abdulloh, 2017).

Teknik dasar memainkan bundengan adalah dipetik dengan tangan kanan memainkan dawai yang berjumlah empat buah, sedangkan tangan kiri memainkan ritmis yang mewakili pola-pola kendang yang berupa pematut. Tangan kanan memainkan pola ajeg yang berisi permainan bendhe, kempul, dan gong, sedangkan tangan kiri memainkan pola-pola kendang yang umumnya berupa pematut. Dengan demikian satu pemain bundengan memainkan dua pola sekaligus dalam repertoarnya. Tembang-tembang yang biasa dilantunkan berasal dari tembang Lengger Wonosoboan seperti Sontoloyo, Sulasih, Kinayakan, dan Gondang Keli. Syair yang terdapat dalam tembang Lengger Wonosoboan umumnya dalam bentuk parikan (pantun) yang biasanya memiliki dua bagian, yaitu bagian sampiran dan bagian isi. Organologi bundengan dapat dilihat pada gambar 5 dengan anak panah biru menunjukkan letak dawai dan anak panah kuning menunjukkan kendang. 


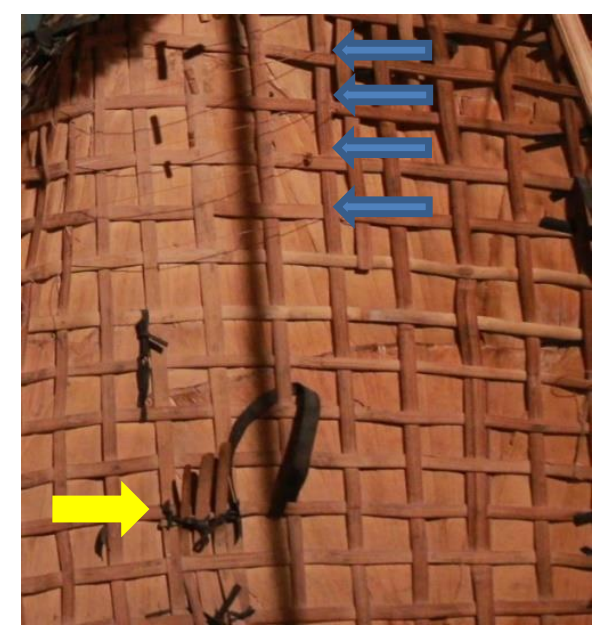

Gambar 5. Kendang dan Dawai pada Instrumen Bundengan

(Dokumentasi: Wahyu Prasetyo, 2017)

Hal yang biasa dilakukan dalam teknik permainan instrumen bundengan adalah permainan dua ricikan secara bersamaan yang dimainkan oleh satu orang pemain. Pembagian ricikan tersebut dimainkan dua tangan dengan tangan kiri memainkan ricikan kendang, sedangkan tangan kanan memainkan ricikan dawai. Adapun teknik dasarnya adalah dengan memetik sumber bunyi menggunakan jari tangan yang dapat dilihat pada gambar 6.

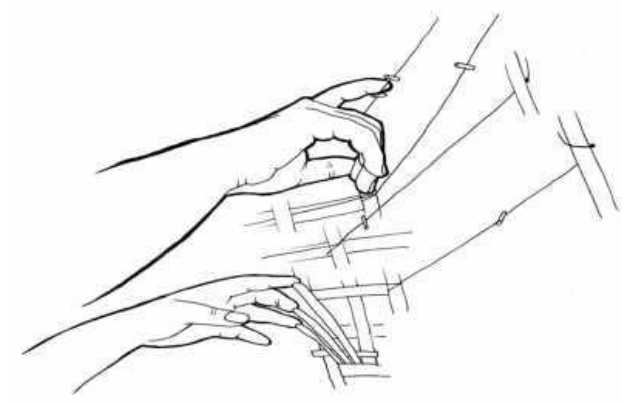

Gambar 6. Ilustrasi teknik memainkan bundengan dengan kedua tangan

(Ilustrasi: Vivien Sarkany 2016 diambil dari Sa'id Abdulloh)

Teknik memetik sumber bunyi pada gambar 6, tentunya akan menghasilkan bunyi sesuai dengan karakter suara dasar yang dimiliki masing-masing ricikan. Namun terdapat teknik-teknik tertentu khususnya dalam memainkan ricikan kendang yaitu teknik pithet. Teknik tersebut dapat membunyikan karakter bunyi tak, dhet dan ket pada kendang dengan cara meredam bilah bambu dengan jari tengah ketika dipetik. Masing-masing memiliki cara peredaman yang berbeda-beda. Untuk dapat membunyikan suara tak, bilah bambu tengah dipetik menggunakan jari telunjuk sembari menempatkan jari tengah untuk meredam getaran secara utuh. Bunyi dhet dilakukan dengan cara yang sama namun dengan 
redaman yang relatif sedikit, sedangkan untuk bunyi ket juga dengan teknik yang sama namun intensitas petikan jari telunjuk dengan dinamika yang rendah. Contoh ilustrasi teknik pithet dalam permainan kendang bundengan dapat dilihat pada gambar 7 .

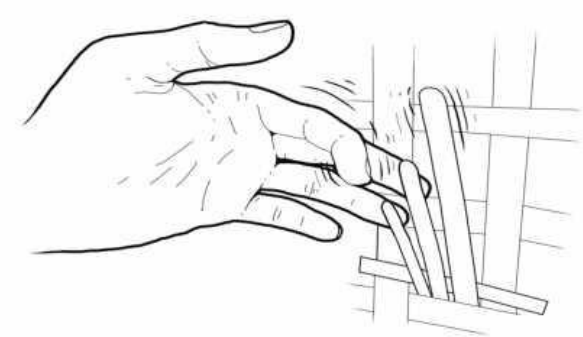

Gambar 7. Teknik pithet dalam permainan kendang bundengan (Ilustrasi: Vivien Sarkany 2016 diambil dari Sa'id Abdulloh)

Beberapa bagian lain terkait teknik permainan kendang pada instrumen bundengan adalah penyederhanaan kendangan secara umum. Meskipun secara bunyi merupakan imitasi dari kendang membran, namun tidak semua karakter bunyi pada kendang membran dapat diaplikasikan. Hal tersebut wajar terjadi karena sifat fisis dari dua instrumennya berbeda. Namun demikian untuk menutupi kekurangan tersebut dilakukan penyederhanaan teknik permainannya. Adapun beberapa hal yang disederhanakan dalam teknik permainan kendang pada instrumen bundengan dapat dilihat pada tabel 1.

Tabel 1. Penyederhanaan teknik permainan kendang bundengan

\begin{tabular}{|c|c|}
\hline $\begin{array}{c}\text { Bunyi yang dihasilkan pada teknik } \\
\text { permainan kendang membran }\end{array}$ & $\begin{array}{c}\text { Penyederhanaan dalam teknik } \\
\text { permainan kendang bundengan }\end{array}$ \\
\hline Tulung $\left(t^{\circ}\right)$ & $\overline{\overline{P P}}$ \\
\hline Dlung $(b)$ & $\overline{\mathrm{Db}}$ \\
\hline Plak $\left(P^{\circ}\right)$ & $\overline{\overline{P t}}$ \\
\hline
\end{tabular}

*Sumber: Sa'id Abdulloh, 2017

Materi permainan kendang merupakan bentuk kendangan pematut yang sering diterapkan dalam iringan tembang. Asumsinya agar tercapai alur sajian yang paling sesuai dengan warna musikal dari instrumen bundengan. Umumnya materi permainan kendang disajikan dengan skema buka, irama I, irama II, peralihan, dan suwuk. Contoh pola kendang dalam permainan instumen bundengan dalam lagu Sulasih dapat dilihat pada partitur 1. 


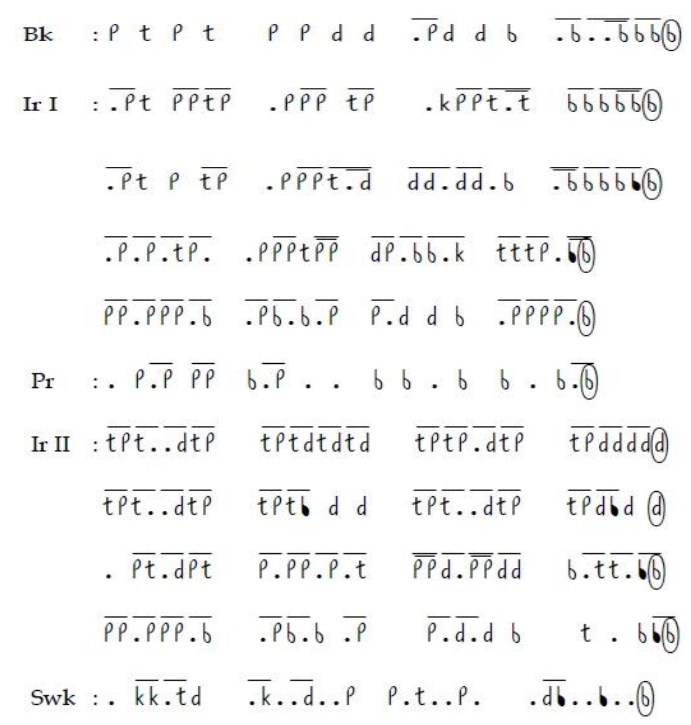

Partitur 1. Kendang bundengan

(Sumber: Sa'id Abdulloh, 2017)

Pada pola kendang di partitur 1 menunjukkan bahwa pola sajian kendang umumnya disusun dengan sekaran-sekaran pematut agar terjalin dengan bentuk sajian lagu. Sekaran pada partitur 1 tidak seutuhnya sama apabila disajikan dengan lagu lain seperti Sarindoro, Kinayakan, dan Gondang Keli. Hal itu disebabkan karena panutan dalam permainan menggunakan kendangan pematut yang secara garis besar berupa improvisasi. Namun demikian skema atau pola yang digunakan umumnya berbentuk seperti contoh notasi di partitur 1, oleh karena itu penerapan dalam permainan kendang sangat kondisional agar dapat menyesuaikan dengan lagu yang disajikan.

Pola yang dimainkan dalam ricikan dawai pada instrumen bundengan memiliki fungsi seperti ricikan struktural pada ketuk, kenong kempul, dan gong dalam sajian karawitan Jawa. Hal tersebut disebabkan tindakan imitasi bunyi yang diciptakan pada dawai berasal dari ricikan struktural, khususnya bendhe, kempul, dan gong yang terdapat pada karawitan Lengger Wonosobo. Akibatnya pola tabuhan yang dilakukan adalah transmedium dari bendhe, kempul dan gong ke dalam petikan dawai.

Dawai yang memainkan pola tabuhan bendhe terletak pada dawai 1 dan 2 (lihat konstruksi instrumen) yang dipetik secara bergantian dengan penempatan hitungan ganjil dan genap di setiap gatra (hitungan 4/4). Dawai 1 terletak pada hitungan ganjil dan dawai 2 terletak pada hitungan genap. Sedangkan pola tabuhan kempul dan gong yang terletak pada dawai 3 dan 4 (lihat konstruksi instrumen) dimainkan pada setiap akhir gatra di mana dawai 3 terletak pada akhir gatra ganjil sedangkan dawai 4 terletak di bagian akhir gatra 
empat. Berikut pola kempul dan gong di bawah ini. Agar lebih mudah memahami pola permainan dawai bundengan dalam setiap ketukan dan nada yang dihasilkannya dapat dilihat pada tabel 2 .

Tabel 2. Pola permainan dawai bundengan

\begin{tabular}{|llll|llll|llll|llll|l|}
\hline 1 & 2 & 1 & 3 & 1 & 2 & 1 & & 1 & 2 & 1 & 3 & 1 & 2 & 1 & 4 & Angka dawai \\
\hline 6 & 3 & 6 & 6 & 6 & 3 & 6 & 6 & 6 & 3 & 6 & 6 & 6 & 3 & 6 & 3 & Nada dawai \\
\hline
\end{tabular}

*Sumber: Sa'id Abdulloh, 2017

Pola permainan pada tabel 2 adalah pola permainan dawai bundengan yang merepresentasikan suara alat musik bendhe untuk senar 1 dan 2, kempul untuk senar 3, dan gong untuk senar 4. Angka dawai menunjukan posisi senar bundengan, sedangkan nada dawai merupakan frekuensi nada yang dihasilkan dalam tangga nada pentatonis Jawa. Berdasarkan susuna pola pada tabel 2 maka terlihat jalinan struktur permainan yang memiliki kedudukan sebagai pola ritme. Pola-pola tersebut dipastikan berjalan terus menerus dari awal hingga akhir sajian yang dilakukan. Selain itu, apapun lagu yang dibawakan dalam pertunjukannya juga menggunakan pola tersebut. Dengan demikian pola permainan pada dawai bundengan dapat dikategorikan ke dalam pola ajeg.

Lagu atau tembang merupakan unsur musikal lain dalam sajian musik bundengan. Peranan tembang dapat dilakukan sendiri sembari melakukan permainan instrumen atau melibatkan satu atau dua orang lain untuk menyajikannya. Tembang memiliki peran yang signifikan untuk menghasilkan sajian musik menjadi lebih bermakna dalam tema, karakter, maupun sifat lagu yang dibawakan. Hal itu dituangkan ke dalam teks atau cakepan berbentuk parikan yang sebagian besar sudah melekat pada tembang-tembang lenggeran. Sesuai dengan teks atau cakepan yang cenderung berbentuk parikan, maka formatnya dibagi dalam bait dimana satu bait terdapat empat kalimat lagu. Namun demikian struktur yang digunakan tidak terpaku pada struktur parikan secara umum, yang mengacu jumlah suku kata pada satu kalimatnya. Demikian pula jumlah kalimat dalam sampiran maupun isi. Semua ketentuannya tergantung dari judul atau nama parikan yang digunakan.

Jumlah bait tidak memiliki batasan, karena seringkali seniman menggarap ulang teks tersebut dengan menambahkan teks lain sesuai dengan selera senimannya. Seniman tidak terpaku pada teks asli dari lagu, akan tetapi pada kontur nada tetembangan yang sudah melekat dalam identitas lagunya. Pada keadaan itulah seniman sering mengubah kandungan teks dalam sajian vokalnya dengan tujuan pesan-pesan atau maknanya lebih 
mudah dipahami. Adapun nyanyian dalam sajian musik bundengan dapat dilihat pada partitur 2.

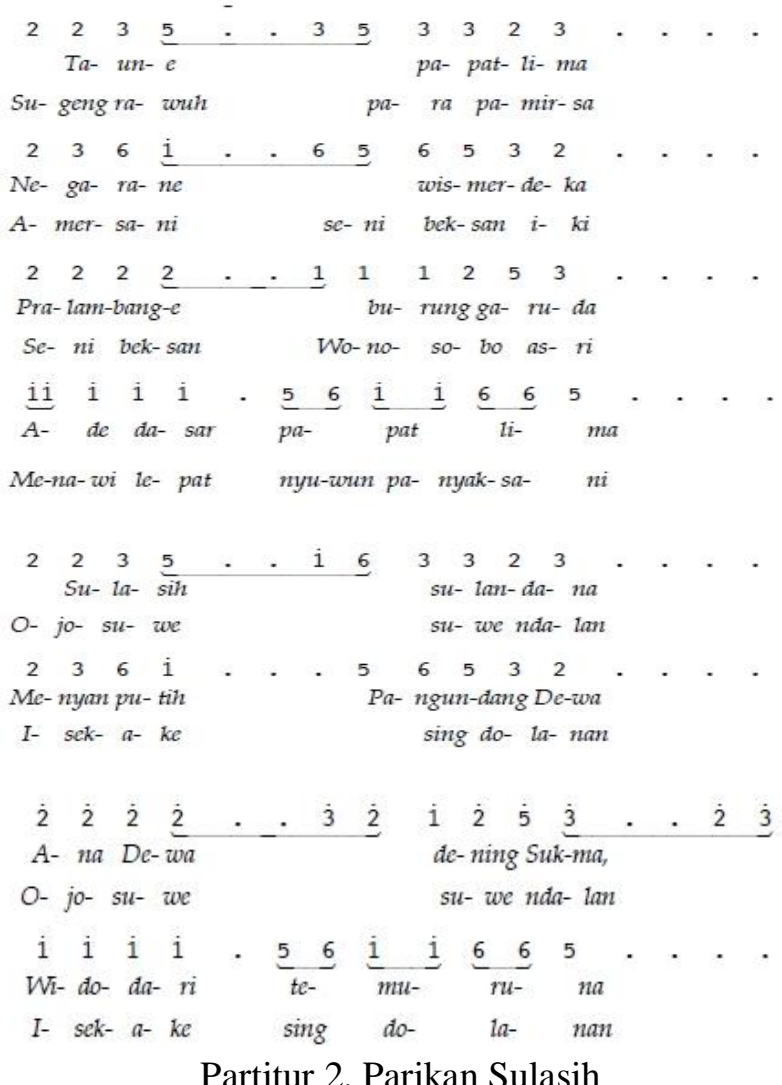

(Sumber: Sa'id Abdulloh, 2017)

Penyajian kesenian bundengan terdiri dari satu orang pemain yang sekaligus merangkap sebagai wiraswara dan dua penari Lengger Topeng yang terdiri dari satu penari laki-laki dan satu penari perempuan. Musik bundengan pada awalnya memang permainan one man show, dimana hanya ada satu orang saja yang terlibat di dalamnya. Namun dalam seni pertunjukan modern, musik Bundengan sering digunakan untuk mengiringi tari khas daerah Wonosobo seperti Lengger Topeng yang dapat dilihat pada gambar 8, dengan iringan tembang-tembang setempat seperti Sulasih, Kebo Giro, Sontoloyo. 


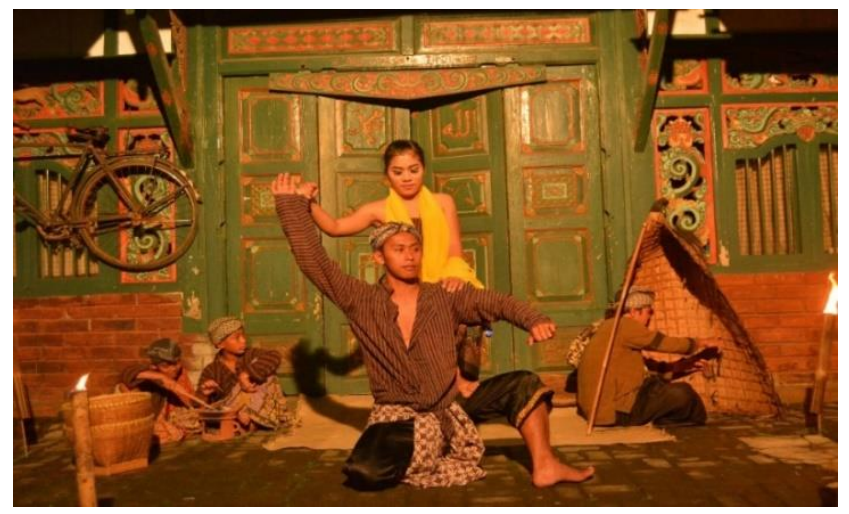

Gambar 8. Bentuk Penyajian Kesenian Bundengan

(Dokumentasi: Bahtiar Arbi, 2017)

Pertunjukan bundengan sebenarnya tidak mempunyai urutan yang pasti, karena pada dasarnya memang bukan merupakan seni pertunjukan. Saat pengambilan data di lapangan, tembang yang dinyanyikan yaitu Sulasih dan Kebo Giro, untuk mengiring tari Lengger Topeng. Tuning yang digunakan menyesuaikan timbre dari suara bendhe, kempul, dan gong, yang berlaras pelog. Pada awal penyajian irama yang dimainkan masih tenang, penari membentuk pola lantai memutar. Kemudian, ketika irama yang dimainkan semakin cepat, penari juga mengikuti irama dengan puncaknya ketika penari perempuan menaiki bahu penari laki-laki sembari berdiri dan kemudian meneruskan pola lantai selanjutnya (lihat gambar 8). Pertunjukan berakhir ketika lagu selesai dan penari perempuan turun dari bahu penari laki-laki.

\section{Fungsi Musik Bundengan}

Bundengan di daerah Wonosobo memiliki beberapa fungsi yang didasarkan dari penjelasan Allan P. Meriam. Hasil yang didapatkan dilapangan menunjukkan bahwa fungsi musik bundengan yaitu sebagai ungkapan emosi, sebagai penghayatan estetis, sebagai hiburan, sebagai komunikasi, sebagai fungsi yang berkaitan dengan norma-norma sosial, sebagai kesinambungan kebudayaan, dan sebagai pengintegrasian masyarakat.

Musik bundengan sebagai media ungkapan estetis senimannya, bahkan suatu kesenian dapat dikatakan sebagai bentuk ekspresi budaya. Bundengan mewakili identitas kebudayaan masyarakat di Wonosobo dan sekitarnya yang memiliki kedekatan budaya. Bundengan mewakili identitas seni kerakyatan yang berbeda dengan seni istana, walaupun kondisi sekarang perbedaan itu hanya terletak dalam konteks kepakeman pertunjukannya dan tidak lagi dari segi filosofis dan hegemoni keseniannya. Selain berperan sebagai media 
ekspresi seni, ungkapan estetis, dan media hiburan, bundengan secara tidak langsung merepresentasikan bahwa seni tidak terbatas pada teks seni semata, namun juga dari segi konteks sosial budayanya.

Pada awal mulanya, seperti diungkapkan oleh Hengky Krisnawan selaku pewaris bundengan milik Barnawi (founding father), bahwasannya bundengan difungsikan sebagai sarana komunikasi dengan media seni. Komunikasi antara manusia dengan manusia, manusia dengan alam, dan manusia dengan Tuhannya. Ada suatu sinergi dalam fungsi komunikasi dengan bundengan sebagai media komunikasi dengan alam, manusia, dan Tuhan. Kompleksitas pola komunikasi terintegrasi satu dengan yang lainnya, yang merefleksikan kandungan filosofis masyarakat pada masanya. Pada saat sekarang ini pola komunikasi semacam itu mengalami reduksi dan sudah beradaptasi sesuai dengan perubahan kondisi sosial budaya masyarakat sekitar.

Bundengan awalnya digunakan untuk menyanyikan tembang-tembang yang berkaitan dengan Ketuhanan, sebagai sebuah ungkapan rasa syukur, perlindungan, dan harapan. Masyarakat berkumpul untuk menyanyikan tembang-tembang secara bersamasama. Pemanfaatan bahan-bahan alami sebagai unsur pembentuk bundengan seperti clumpring, bilah bambu, dan ijuk yang memanifestasikan hubungan erat antara manusia dengan alam, sehingga ada suatu sinergi dalam bentuk komunikasi sosial, budaya, dan ritual kegamaan di dalamnya. Penjelasan penulis didasarkan hasil wawancara terhadap beberapa tokoh seniman dan budayawan yang kebenarannya dapat bersifat relatif.

Di era milenial sekarang ini, musik bundengan lebih berperan sebagai sarana hiburan yang bertujuan untuk tetap melestarikan kesenian yang dulunya langka dan hampir punah. Kemudian secara perlahan, para seniman bundengan muda menggunakan kesenian ini sebagai media edukasi terhadap para generasi muda untuk mengenal alat musik etnik daerah serta mengenal adat budaya setempat. Saat ini, bundengan berhasil menjadi salah satu identitas Wonosobo selain Dieng dan buah caricanya. Fungsi seni tidak hanya terbatas terhadap teks semata, namun juga memengaruhi konteksnya. Seni merupakan ekspresi budaya yang menggambarkan perjalanan sosial budaya di suatu daerah yang syarat akan makna filosofis di dalamnya. Maka dari itu, dapat dikatakan bahwa bundengan adalah salah satu bentuk kesinambungan budaya, selain dari fungsi teks seni itu sendiri yang merepresentasikan ungkapan emosi, penghayatan estetis, dan media hiburan. Bundengan juga berfungsi secara konteks sosial budaya, berkaitan dengan norma-norma sosial dan pengintregasian masyarakat. 


\section{Kesimpulan}

Bundengan merupakan representasi dari masyarakat agraris, dimana bahan dasar pembuatannya berasal dari lingkungan alam sekitar seperti bambu, clumpring dan ijuk. Bundengan berasal dari kowangan yang berbentuk seperti mantel yang berfungsi untuk berlindung dari panas dan hujan, lalu bertransformasi menjadi alat musik bundengan yang meniru suara gamelan. Imitasi suara gamelan yang dapat dimainkan bundengan yaitu bendhe, kempul, gong, dan kendang. Pertunjukan musik bundengan biasanya digunakan untuk mengiringi tarian daerah setempat seperti Lengger dan Soreng, dengan menyanyikan tembang-tembang tradisional yang sudah secara turun temurun dilestarikan.

Bundengan memiliki beberapa fungsi seperti ungkapan emosi, sebagai penghayatan estetis, sebagai hiburan, sebagai fungsi yang berkaitan dengan norma-norma sosial, sebagai kesinambungan kebudayaan, sebagai pengintegrasian masyarakat, dan sebagai komunikasi antara manusia dengan manusia, manusia dengan alam, dan manusia dengan Tuhan. Selain itu bundengan juga mewakili identitas kebudayaan Wonosobo dengan segala kompleksitas adat budayanya yang termanifestasikan melalui bundengan.

\section{Kepustakaan}

Abdulloh, M. S. (2017). Mengenal \& Melestarikan Bundengan sebagai Sarana Edukasi. Workshop Bundengan. Wonosobo.

Cook, R. (2016). This is not a Kowangan. University of Melbourne Faculty of Arts.

Djelantik, A. A. . (1999). ESTETIKA Sebuah Pengantar. Bandung: Masyarakat Seni Pertunjukan Indonesia.

Hengky, B. (2016). Aura Magis Musik Bundengan. Wonosobo: Dinas Pariwisata dan Ekonomi Kreatif Kab. Wonosobo.

Kapoyos, R. J. (2018). Musik Bia: Fungsi Dan Realitas Sosial Pada Masyarakat Di Kabupaten Minahasa Utara. Tonika: Jurnal Penelitian Dan Pengkajian Seni, 1(1), 15-26. Retrieved from http://journal.stt-abdiel.ac.id/tonika/article/view/13

Keen, P. (2017). Bundengan Stories: Folk Zithers and Duck Herders in Wonosobo, Central Java. Retrieved from http://www.auralarchipelago.com/auralarchipelago/bundengan

Kunst, J. (1973). Music in Java, volume 1 dan 2 (E. L. Heins, Ed.). The Hague: Martinus Nijhoff.

Meriam, A. P. (1964). The Antropology Of Music Chicago. North Western University Press.

Miles, \& Huberman. (1992). Analisis Data Kualitatif (T. R. Rohidi, Ed.). Jakarta: UI Press.

Wuryanto, A. (2017). Mengenal \& Melestarikan Bundengan sebagai Sarana Edukasi. Workshop Bundengan. Wonosobo. 


\section{Narasumber}

Agus Wuryanto (51 tahun), pengamat seni. Sidojoyo, Wonosobo.

Bukhori (57 tahun), penembang Bundengan. Dusun Ngabean, Maduretno, Kalikajar, Wonosobo.

Hengky Krisnawan (48 Tahun), pemain Bundengan. Dusun Sruni, Jaraksari, Wonosobo.

M. Sa'id Abdulloh (25 Tahun), pemain Bundengan, Wonosobo.

Mulyani (54tahun), guru seni di SMP 2 Selomerto Wonosobo.

Munir (54 tahun), pemain Bundengan. Dusun Ngabean, Maduretno, Kalikajar, Wonosobo. 